\title{
Anthropometric profile of pediatric patients undergoing allogeneic hematopoietic stem cell transplantation: a single center one-year follow-up study
}

\author{
Marta Krzysztofik ${ }^{1 *}$, Artur Kacprzyk ${ }^{2}$, Anna Aleksandra Skuza ${ }^{1}$, Adam Chmielowski $^{3}$, \\ Jolanta Goździk ${ }^{4}$
}

${ }^{1}$ Students' Scientific Group of Hematopoietic Stem Cell Transplantation, Jagiellonian University Medical College, Kraków, Poland ${ }^{2}$ Doctoral School in Medical and Health Sciences, Jagiellonian University Medical College, Kraków, Poland

${ }^{3}$ J. Dietl Specialist Hospital, Kraków, Poland

${ }^{4}$ Department of Pediatric Transplantation, Clinical Immunology and Transplantation, Jagiellonian University Medical College, Kraków, Poland

\section{Abstract}

Introduction: Hematopoietic stem cell transplantation (HSCT) is an aggressive form of therapy which leads to malnutrition requiring nutritional support. The aim of our study was to evaluate if the growth of children is affected by HSCT and what the relevant factors are.

Methods: We analyzed changes in anthropometric measures of 79 pediatric patients who underwent allogeneic HSCT. Nutritional status was assessed based on weight and height measurements collected prior to HSCT and within 12 months post-transplantation. Body weight and height were referred to the age of patients using available z-score calculators.

Results: Compared to the first measurement, the weight-for-age and height-for-age z-scores were significantly reduced in all following measurements within a 1-year follow-up. The most severe weight loss occurred on the last day of hospitalization related to HSCT, while the height gain declined progressively after HSCT. The presence of acute graft versus host disease (GvHD) and the use of a total body irradiation-based regimen were found to be risk factors for a severe slowdown of weight gain, while acute GvHD of the gastrointestinal tract, chronic GvHD and the use of parenteral nutrition were risk factors for a decline in height gain.

Conclusions: Patients treated with allogeneic HSCT demonstrate a reduction in the pace of growth. HSCT recipients complicated by GvHD require prolonged and close weight and height monitoring.

Key words: children, hematopoietic stem cell transplantation, nutritional assessment, anthropometric profile

Acta Haematologica Polonica 2021; 52, 2: 110-120

\section{Introduction}

Hematopoietic stem cell transplantation (HSCT) is an aggressive form of therapy used for malignant and non-malignant disorders of the hematopoietic system. Over recent years, the annual numbers of both allogeneic and autologous HSCTs have been continuously increasing [1]. Early- and long-term survival rates have improved, and are expected to continue to improve in the coming decades due to the enhancement in human leukocyte antigen (HLA)

\footnotetext{
*Address for correspondence: Marta Krzysztofik,

Jagiellonian University Medical College,

św. Anny 12, 31-008 Kraków, Poland, phone/fax:

+48 1242204 11, e-mail: md.krzysztofik@gmail.coml

Received: 19.08 .2020
}

PTHiT Copyright $\odot 2021$

The Polish Society of Haematologists and Transfusiologists,

Accepted: 21.11 .2020 
typing, conditioning regimens, supportive and post-transplant care [2]. Today, the probability of 10 -year survival is $85 \%$ in 2-year survivors [3].

Nevertheless, there is strong evidence that childhood HSCT survivors carry a significantly higher burden of chronic health conditions related to therapeutic exposures than do patients treated with conventional therapies and non-cancer patients [4]. Taken together, all these factors underscore the need for effective long-term surveillance for screening, prevention and maintaining good quality of life. The nutritional status of HSCT recipients has long been of interest to clinicians. Due to ablative therapy, the intensity of conditioning regimen and underlying disease, the catabolism of the patient increases and leads to malnutrition, which usually requires nutritional support [5]. Other factors contributing to impaired weight and height gain are transplant-related complications such as: mucositis, diarrhea, nausea, vomiting, and anorexia. These are usually related to graft-versus-host disease (GvHD), which interferes with the digestion and absorption of nutrients [5].

Several longitudinal studies have reported a significant decline in final growth of adult cancer survivors, including HSCT recipients [6-8]. The use of total body irradiation and certain conditioning regimens have been associated with the most severe growth deterioration due to their impact on the hypothalamic-pituitary axis and damage to bone epiphyses [9-11]. Moreover, the Childhood Cancer Survivor Study found that patients with certain malignancies are more likely to be underweight as adults and to suffer from serious medical conditions. This demonstrates the need for close surveillance [12].

Since the most dynamic part of the HSCT involves the early period after the HSCT $[13,14]$, patients are at risk of malnutrition, and often require nutritional support. Despite this fact, there is a paucity of data concerning the impact of HSCT on the short-term growth of children, indicating a need for further research on an adequate population. A significant heterogeneity of patient groups is challenging, since malnutrition and short stature are included in the phenotype of some genetic disorders that are treated with HSCT. Therefore, studies reporting short-term anthropometric profiles of patients often include different populations, making proper comparisons problematic $[15,16]$.

Thus, the purpose of this analysis was to assess the changes of anthropometric measures (weight, height) of children who underwent HSCT in a one-year follow-up and to evaluate any potentially relevant risk factors contributing to growth disturbances in this population.

\section{Methods}

\section{Study design}

In this single-institution, retrospective cohort study, we enrolled 79 pediatric (under the age of 18) patients who received hematopoietic stem cells (HSC) at the Transplantation Center, Children's University Hospital in Krakow, Poland between December 2005 and March 2019. The medical records of eligible patients were reviewed and the results were drawn up based on a database created by the authors. This study was designed and described according to the STROBE guidelines for observational studies (Table S1 in Supplement 1) [17].

\section{Treatment protocol}

The transplant procedure was conducted according to institutional procedures and a suitable treatment protocol.

\section{Anthropometric profile}

The anthropometric profile of patients was assessed based on body weight and height measurements (SECA 799 Class III Approved Electronic Column Scale with BMI function). Calculations based on Center for Diseases Control (Medscape, CDC) growth charts were used to determine weight-for-age and height-for-age percentiles and z-scores in all children. The measurements were made during scheduled medical check-ups as part of the post-transplant surveillance process. Data concerning patients' body weight and height were collected at four time points:

1) up to seven days before HSCT - on admission

2) on the last day of hospitalization related to HSCT - on discharge

3) $100( \pm 14)$ days post-HSCT

4) $365( \pm 30)$ days post-HSCT.

The nutritional status of patients was described based on percentile values. Patients were classified as underweight ( $<5$ percentile), healthy weight ( $\geq 5$ and $<85$ percentile), overweight ( $\geq 85$ and $<95$ percentile), or obese ( $\geq 95$ percentile) according to their weight; and as short stature ( $<5$ percentile), normal stature ( $\geq 5$ and $<95$ percentile), or tall stature ( $\geq 95$ percentile) according to their height.

\section{Eligibility criteria}

Eligible patients were those who underwent allogeneic HSCT between December 2005 and March 2019 and whose weight and height measurements were collected at all the designated time points. To reduce the risk of confounding factors, patients with primary immunodeficiencies or other genetic conditions associated with short stature were excluded. Other exclusion criteria were: subsequent HSCT, death for any reason before the fourth measurement, insufficient information in the medical records, HSCT-related hospitalization longer than 86 days, or a period between second and third measurements shorter than two weeks. None of the patients had received growth hormone $(\mathrm{GH})$ therapy within the 12 months prior to HSCT nor in the 12 months after HSCT. A flowchart outlining the inclusion process is presented in Figure 1. 


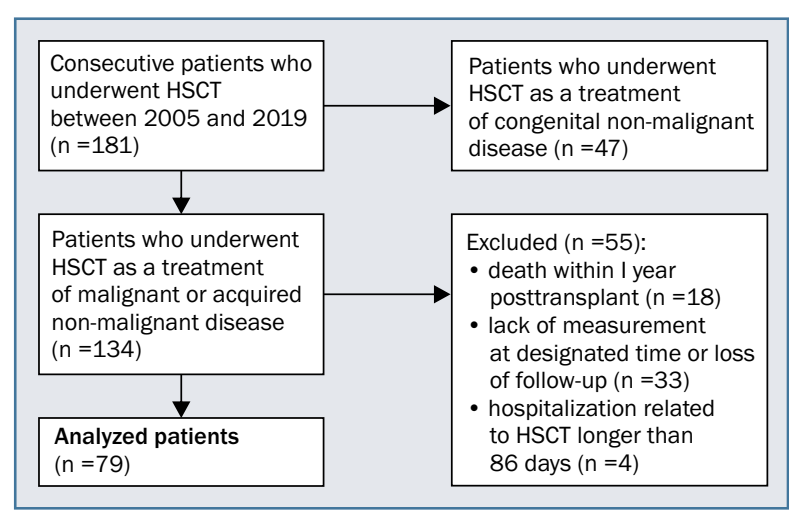

Figure 1. Flowchart of patient inclusion

\section{Measured outcomes}

The primary endpoints of our study included an evaluation of patients' anthropometric profiles within one year after transplantation, i.e. changes of weight-for-age and height-for-age z-scores in four time points.

The secondary endpoints comprised analysis of potentially relevant factors contributing to growth slowdown. We analyzed differences between first and fourth measurements in weight-for-age and height-for-age z-scores in subgroups derived from selected baseline characteristics of patients and transplant complications. These included: age ( $<10$ and $\geq 10$ years), sex, type of disease, type of pre-transplant conditioning, the use of total body irradiation (TBI)-based regimen and parenteral nutrition, the presence of stage III-IV mucositis, acute GvHD (graded according to Keystone Consensus [18]), acute GvHD of the gastrointestinal (GI) tract, chronic GvHD (diagnosed within 365 days after transplantation), and chronic GvHD of the Gl tract.

\section{Statistical analysis}

Prior to statistical analysis, all patients with missing data or who were lost to follow-up were excluded. Continuous variables are presented as mean \pm standard deviation (SD) or median and interquartile range [IQR], as appropriate. Categorical variables are expressed as numbers and percentages. For normality assessment, the Shapiro-Wilk test was used. Continuous variables were compared between two related and non-related groups using the Wilcoxon signed-rank test and Mann-Whitney U test, respectively. P-values of less than 0.05 were considered statistically significant. Data analysis was done with STATISTICA 13.0 software (StatSoft Inc., Tulsa, OK, USA).

\section{Ethical statement}

All procedures performed in this study involving human participants were in accordance with the ethical standards of the institutional and national research committee and with the 1964 Helsinki Declaration and its later amendments or comparable ethical standards. Informed consent was not required in this type of study. This study was approved by the Ethics Committee of Jagiellonian University.

\section{Results}

\section{Patient characteristics}

A total of 79 pediatric patients (54 male, 25 female) underwent allogeneic HSCT as a treatment for malignant disease $(61 ; 77.22 \%)$ or acquired non-malignant disease (18; $22.78 \%)$. The mean \pm SD age on admission was 116.32 \pm 58.79 months. Fifty-eight (73.42\%) patients received pre-transplant myeloablative therapy, and in 31 (39.24\%) of them a TBI-based regimen was used. Forty-seven (59.49\%) patients received $\mathrm{HSC}$ from an unrelated donor and 32 (40.51\%) from a related donor, comprising 28 from an HLA-matched sibling donor (35.44\%), and four from an HLA-family donor (5.06\%). Donors were men in 43 (54.43\%) cases and women in 36 (45.57\%) cases, with a mean age of $23.53 \pm 10.23$ years. Bone marrow was a graft source in $74(93.67 \%)$ patients, peripheral stem cells were used in four $(5.06 \%)$ patients, and cord blood in one $(1.27 \%)$ patient. Hematopoietic reconstitution was completed in all patients. The median (IQR) length of hospitalization related to HSCT was 36 (32-44) days. The time between first and third measurements was 97 (91-104) days, and between first and fourth measurements was 362 (356-373) days. Transplant-related complications included mucositis in 69 (87.34\%) patients, acute GvHD in 26 (34.57\%), chronic GvHD in 25 (31.65\%), fever of unknown origin in 59 (74.68\%), veno-occlusive disease in three (3.80\%), and engraftment syndrome in 11 (13.92\%). Patient and transplant characteristics are set out in Table I.

\section{Primary endpoints}

The anthropometric profiles of all eligible $(n=79)$ patients were expressed as mean values with standard deviations of weight-for-age and height-for-age z-scores (Figures $2 \mathrm{~A}$ and $2 \mathrm{~B}$ ).

\section{Weight}

At baseline, four (5.06\%) patients were classified as underweight, 52 (65.82\%) as healthy weight, 16 (20.25\%) as overweight, and seven (8.86\%) as obese. The mean values of weight were $36.37 \mathrm{~kg}, 33.89 \mathrm{~kg}, 34.71 \mathrm{~kg}$ and $37.66 \mathrm{~kg}$ at the first, second, third and fourth measurements, respectively. The weight-for-age z-scores in subsequent measurements were: $0.11,-0.39,-0.35$ and -0.21 , respectively. Compared to the first measurement (on admission), the weight-for-age z-scores were significantly reduced in all following measurements within the 1-year follow-up (Table II). The lowest value of weight-for-age z-scores was noted at the second measurement (on discharge). 
Table I. Demographics of patients and hematopoietic stem cell transplantation (HSCT) characteristics

\begin{tabular}{|c|c|c|c|c|c|}
\hline Parameter & $n$ & Number of patients & Parameter & $n$ & Number of patients \\
\hline Sex, $n$ (\% of males) & 79 & $54(68.35 \%)$ & Peripheral blood stem cells & 79 & $4(5.06 \%)$ \\
\hline Age on admission (months), & 79 & $116.32 \pm 58.79$ & Cord blood & 79 & $1(1.27 \%)$ \\
\hline mean $\pm S D$ & & & HLA-matching, $n$ [\%] & 79 & $62(78.48 \%)$ \\
\hline Age group, $\mathrm{n}(\%)$ & & & Myeloablative conditioning, & 79 & $58(73.42 \%)$ \\
\hline$<10$ years & 79 & $40(50.63 \%)$ & $\mathrm{n}[\%]$ & & \\
\hline$\geq 10$ years & 79 & $39(49.37 \%)$ & TBI-based regimen, $\mathrm{n}[\%]$ & 79 & 31 (39.24\%) \\
\hline Transplant indication, $n(\%)$ & & & Hematopoietic reconstitution, & 79 & 79 (100.00\%) \\
\hline Malignant & 79 & 61 (77.22\%) & $\mathrm{n}[\%]$ & & \\
\hline Non-malignant & 79 & $18(22.78 \%)$ & $\begin{array}{l}\text { Parenteral nutrition in HSCT } \\
\text { period, } n[\%]\end{array}$ & 79 & $50(63.29 \%)$ \\
\hline Disease, $n(\%)$ & & & Time between HSCT and second & 79 & 36.00 \\
\hline $\begin{array}{l}\text { Acute lymphoblastic leukemia } \\
\text { (ALL) }\end{array}$ & 79 & 32 (40.51\%) & $\begin{array}{l}\text { measurement (days), median } \\
{[\mathrm{IQR}]}\end{array}$ & & [32.00-44.00] \\
\hline Severe aplastic anemia (SAA) & 79 & $19(24.05 \%)$ & Time between HSCT and third & 79 & 97.00 \\
\hline Acute myeloid leukemia (AML) & 79 & $13(16.46 \%)$ & measurement (days), median & & {$[91.00-104.00]$} \\
\hline $\begin{array}{l}\text { Myelodysplastic syndrome } \\
\text { (MDS) }\end{array}$ & 79 & $4(5.06 \%)$ & $\begin{array}{l}{[\mathrm{IQR}]} \\
\text { Time between HSCT and fourth }\end{array}$ & 79 & 362.00 \\
\hline $\begin{array}{l}\text { Juvenile chronic myeloid leuke- } \\
\text { mia (JMML) }\end{array}$ & 79 & $3(3.80 \%)$ & $\begin{array}{l}\text { measurement (days), median } \\
{[\mathrm{IQR}]}\end{array}$ & & [356.00-373.00] \\
\hline Autoimmune disease & 79 & $2(2.53 \%)$ & $\begin{array}{l}\text { Transplant complications, } \\
\mathrm{n}[\%]\end{array}$ & & \\
\hline Chronic myeloid leukemia (CML) & 79 & $2(2.53 \%)$ & Mucositis: & 79 & \\
\hline $\begin{array}{l}\text { Hemophagocytic lymphohistiocy- } \\
\text { tosis (HLH) }\end{array}$ & 79 & $2(2.53 \%)$ & - stage I-II & 19 & $35(44.30 \%)$ \\
\hline Non-Hodgkin's lymphoma (NHL) & 79 & $2(2.53 \%)$ & - stage III-IV & & $34(43.04 \%)$ \\
\hline Disease stage & & & Acute GvHD: & 79 & $26(34.57 \%)$ \\
\hline before HSCT, n [\%] & & & - stage I-II & & 19 (24.05\%) \\
\hline No remission & 79 & $34(43.04 \%)$ & - stage III-IV & & $7(8.86 \%)$ \\
\hline CR I & 79 & $21(26.58 \%)$ & - gastrointestinal tract & & $13(17.28 \%)$ \\
\hline CR II & 79 & $23(29.11 \%)$ & - liver & & $3(4.94 \%)$ \\
\hline $\mathrm{CR}>\mathrm{II}$ & 79 & $1(1.27 \%)$ & - skin & & 25 (33.33\%) \\
\hline Donor type, $n[\%]$ & & & Fever of unknown origin & 79 & $59(74.68 \%)$ \\
\hline MSD & 79 & $28(35.44 \%)$ & Veno-occlusive disease & 79 & $3(3.80 \%)$ \\
\hline MUD & 79 & $47(59.49 \%)$ & Engraftment syndrome & 79 & $11(13.92 \%)$ \\
\hline MFD & 79 & $4(5.06 \%)$ & Chronic GvHD: & 79 & 25 (31.65\%) \\
\hline Donor age (years), mean $\pm S D$ & 79 & $23.53 \pm 10.23$ & - gastrointestinal tract & & $12(15.19 \%)$ \\
\hline Donor sex, $\mathrm{n}$ (\% of males) & 79 & $43(54.43 \%)$ & - skin & & 19 (24.05\%) \\
\hline Source of stem cells, $n$ [\%] & & & - liver & & $11(13.92 \%)$ \\
\hline Blood marrow & 79 & 74 (93.67\%) & - lungs & & $9(11.39 \%)$ \\
\hline
\end{tabular}

SD - standard deviation; CR - complete remission; MSD - matched-sibling donor; MUD - matched-unrelated donor; MFD - matched-family donor; HLA - human leukocyte antigen; TBI - total body irradiation; IQR - interquartile range; GvHD - graft-versus-host disease

Height

In the first measurement, four (5.06\%) patients were classified as short stature, 71 (89.87\%) as normal stature, and four $(5.06 \%)$ as tall stature. Patients' mean height expressed in meters was 1.34, 1.34, 1.35 and 1.38 in the first, second, third and fourth measurements, respectively. The mean height-for-age z-scores were: $-0.03,-0.15,-0.15$, -0.34 . Similarly to weight, the height-for-age z-scores in the second, third and fourth measurements were significantly diminished compared to the first measurement (Table II). But in contrast to the weight profile, the greatest drop in height-for-age values occurred at one year post-transplant. 


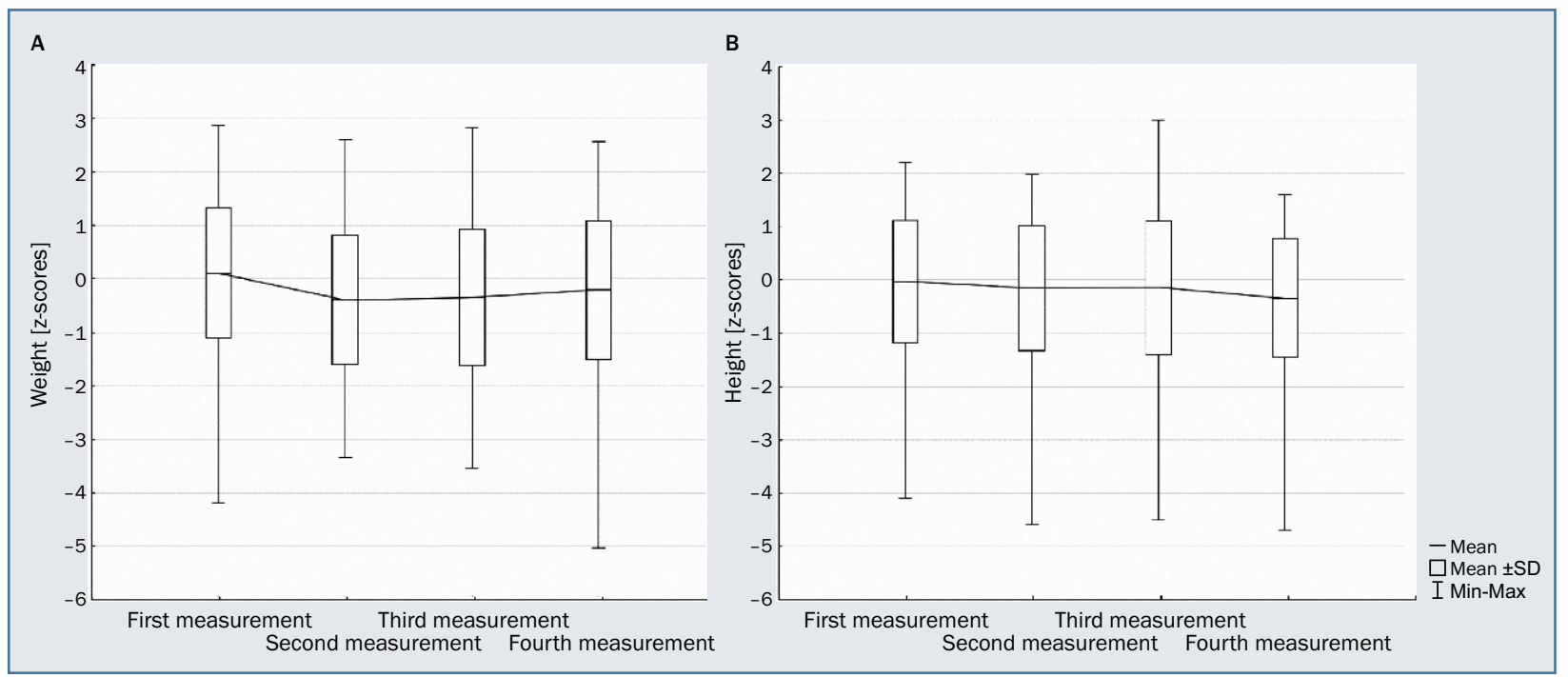

Figure 2. Charts presenting mean \pm standard deviation (SD) values of z-scores of A - weight, $B$ - height, measured at designated time points

Table II. Patient weight in kilograms and height in meters with z-scores at four time points. All values expressed as mean \pm standard deviation $(\mathrm{SD}$

\begin{tabular}{|c|c|c|c|c|c|c|c|c|c|c|c|c|c|c|c|}
\hline \multirow[t]{2}{*}{ Variable } & \multicolumn{3}{|c|}{ Before HSCT } & \multicolumn{4}{|c|}{ On discharge } & \multicolumn{4}{|c|}{100 days post-HSCT } & \multicolumn{4}{|c|}{1 year post-HSCT } \\
\hline & $n$ & [kg] & $\begin{array}{c}\text { [z-sco- } \\
\text { re] }\end{array}$ & $\mathrm{n}$ & [kg] & $\begin{array}{c}\text { [z-sco- } \\
\text { re] }\end{array}$ & p-value* & $\mathrm{n}$ & [kg] & $\begin{array}{c}\text { [z-sco- } \\
\text { re] }\end{array}$ & $\begin{array}{l}\text { p-va- } \\
\text { lue** }\end{array}$ & $n$ & [kg] & $\begin{array}{c}{[z-} \\
\text {-score] }\end{array}$ & $p$-value $* * *$ \\
\hline \multirow[t]{2}{*}{ Weight } & 79 & $\begin{array}{c}36.37 \\
\pm 19.16\end{array}$ & $\begin{array}{r}0.11 \\
\pm 1.21\end{array}$ & 79 & $\begin{array}{c}33.89 \\
\pm 17.83\end{array}$ & $\begin{array}{l}-0.39 \\
\pm 1.21\end{array}$ & $<0.001$ & 79 & $\begin{array}{r}34.71 \\
\pm 17.63\end{array}$ & $\begin{array}{l}-0.35 \\
\pm 1.28\end{array}$ & $<0.001$ & 79 & $\begin{array}{c}37.66 \\
\pm 18.14\end{array}$ & $\begin{array}{c}-0.21 \\
\pm 1.3\end{array}$ & $<0.001$ \\
\hline & $n$ & {$[\mathrm{~m}]$} & $\begin{array}{c}\text { [z-sco- } \\
\text { re] }\end{array}$ & $\mathrm{n}$ & {$[\mathrm{m}]$} & $\begin{array}{c}\text { [z-sco- } \\
\text { re] }\end{array}$ & p-value* & $\mathrm{n}$ & {$[\mathrm{m}]$} & $\begin{array}{c}\text { [z-sco- } \\
\text { re] }\end{array}$ & $\begin{array}{l}\text { p-va- } \\
\text { lue** }\end{array}$ & $n$ & {$[\mathrm{~m}]$} & $\begin{array}{c}{[z-} \\
\text {-score] }\end{array}$ & p-value $* * *$ \\
\hline Height & 79 & $\begin{array}{c}1.34 \\
\pm 0.29\end{array}$ & $\begin{array}{l}-0.03 \\
\pm 1.15\end{array}$ & 79 & $\begin{array}{c}1.34 \pm \\
0.29\end{array}$ & $\begin{array}{l}-0.15 \\
\pm 1.18\end{array}$ & $<0.001$ & 79 & $\begin{array}{c}1.35 \\
\pm 0.28\end{array}$ & $\begin{array}{l}-0.15 \\
\pm 1.25\end{array}$ & 0.002 & 79 & $\begin{array}{c}1.38 \\
\pm 0.27\end{array}$ & $\begin{array}{l}-0.34 \\
\pm 1.12\end{array}$ & $<0.001$ \\
\hline
\end{tabular}

*Second vs. first measurement in z-scores; **third vs. first measurement in z-scores; ***fourth vs. first measurement in z-scores; HSCT - hematopoietic stem cell transplantation

The differences in the weight-for-age and height-for-age z-scores between the fourth and the first measurements are shown in Figure 3.

\section{Secondary endpoints}

At one year post-transplant, declines in weight-for-age and height-for-age z-scores had occurred in all analyzed subgroups. Acute GvHD and the use of a TBI-based conditioning regimen were the significant factors influencing weight (mean $\pm S D$ difference in weight-for-age z-scores values: $-0.53 \pm 1.19$ vs. $-0.22 \pm 0.83$, for patients with and without acute GvHD, respectively, and $-0.59 \pm 0.88$ vs. $-0.14 \pm 0.98$, for patients who received and did not receive $\mathrm{TBI}$, respectively). Other analyzed factors, which were sex, age ( $<10$ years vs. $\geq 10$ years), type of disease (malignant vs non-malignant), parental nutrition in HSCT period, the presence of III-IV mucositis, acute GvHD of the Gl tract, chronic GvHD, as well as chronic GvHD of

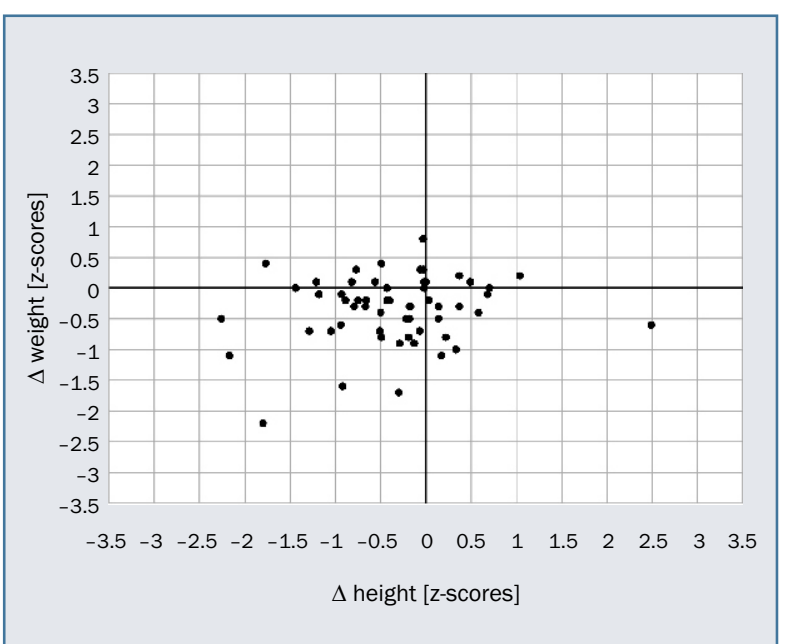

Figure 3. Differences between fourth [365 days after hematopoietic stem cell transplantation (HSCT)] and first (on admission) measurements expressed in z-scores. Each point refers to one patient 
the GI tract, were not significantly associated with the weight difference.

Our analysis of differences in height-for-age z-scores revealed that patients with GI manifestation of acute GVHD and with chronic GVHD presented significantly greater decreases in height gain than did patients without these complications (mean $\pm S D$ difference in height-for-age z-scores values: $-0.51 \pm 1.31$ vs. $-0.23 \pm 0.53$ for patients with and without acute GvHD of GI tract, respectively, and $-0.41 \pm 1.08$ vs. $-0.22 \pm 0.45$ for patients with and without chronic GvHD, respectively). Moreover, patients who received parenteral nutrition during the peritransplant period presented a greater decline in height gain than did those without parenteral nutrition (mean \pm SD difference in height-for-age z-scores values: $-0.39 \pm 0.83$ vs. $-0.08 \pm 0.39$ for patient with and without parenteral nutrition, respectively; $p=0.006)$. Sex, age ( $<10$ years vs. $\geq 10$ years), type of disease (malignant vs non-malignant), the use of TBI, the presence of III-IV mucositis, acute GvHD and GI manifestation of chronic GrHD were not significantly associated with height differences. The results of the comparisons are set out in Table III.

\section{Discussion}

Our study aimed to assess the influence of HSCT on the growth and body mass of children with malignant or acquired non-malignant diseases in a one-year follow-up. We found that patients treated with allogeneic HSCT demonstrated a severe reduction in the pace of growth, and were unable to achieve their baseline z-score values one-year post-transplant.

Moreover, we demonstrated that the presence of acute and chronic GvHD, Gl manifestation of acute GvHD, as well as the use of TBI-based regimens and parenteral nutrition, are potential risk factors for a severe slowdown of growth. HSCT is a commonly used therapeutic procedure for malignant and non-malignant disorders of the hematopoietic system. In most cases, it comprises myeloablative radio- or chemotherapy, infusion of hematopoietic stem cells, and complex immunosuppression [19]. The most dynamic part of the procedure involves the early period after HSCT $[13,14]$. As a result of ablative therapy, the intensity of the conditioning regimen, and the underlying disease, the catabolism of the patient increases and can lead to malnutrition, often requiring nutritional support [5]. Other factors contributing to possible weight loss are transplant-related complications such as: mucositis, diarrhea, nausea, vomiting, and anorexia. These are usually related to GvHD, which interferes with the digestion and absorption of nutrients [5]. Since nutritional status is an essential factor in determining the proper development and health status of children, it is of interest to many clinicians. Several studies have assessed the impact of nutritional status prior to HSCT on its outcomes, but their results remain ambiguous, particularly in pediatric populations.

The aim of our study was to analyze the anthropometric profile of patients before and up to one year after HSCT. We found a significant weight loss and a slowdown in height gain in the early period after transplantation. The height gain continued to slow down until one year post-transplant, but a catch-up in weight occurred. Despite that, children did not reach their baseline z-score values one-year post-transplant. To date, only a few studies have reported the short-term follow-up nutritional profiles of pediatric HSCT recipients with various underlying conditions. Some of them have aimed to determine the efficacy and outcomes of enteral and/or parenteral nutrition and reported short-term evaluations of nutritional status [20-23]. Patients receiving enteral nutrition had lower weight-for-height z-scores than those receiving parenteral nutrition on admission and 30 days post-transplant [20]. Analysis of the anthropometric profile of patients with Fanconi anemia showed a significant decline in nutritional status (weight loss and decrease in height-for-age and BMI-for-age z-scores) at 30 days after HSCT [16]. Campos et al. [24] found no significant reduction in z-scores for weight-for-age, height-for-age, or body mass index (BMI)-for-age in 25 children at 12 -months post-transplant. A recent study on 27 children with primary immunodeficiencies showed a progressive catch up for weight $(-0.27)$ but no catch up for height $(-0.93)$ in a one-year follow up after a primary decrease in anthropometric measures soon after HSC [15]. This is wholly consistent with our findings. Nonetheless, before transplantation mean weight and height z-scores of those patients were below average, and one-third of children had a weight and/or height $\leq-2$ SD, in contrast to our population which was above average $(0.11 \mathrm{z}$-score for height and -0.03 z-score for weight), with only $5 \%$ of our patients being below the $5^{\text {th }}$ percentile of weight and height. Given that we excluded patients with genetic non-malignant conditions, our study group would seem to reflect a healthy population and to be a good model to show alterations in growth patterns.

HSCT is a factor demonstrated as altering final height of children in a longitudinal follow-up [6-8]. Growth deficits have been associated with cranial radiotherapy, spinal irradiation of $\geq 7$ vertebrae, administration of certain conditioning regimens (lomustine, busulfan), pre-transplant body height, and young age [9, 25]. Among these factors, conditioning regimens (total body irradiation, busulfan, cyclophosphamide, melphalan) have been found to be one of the most important factors affecting final height of cancer survivors, as they exert an effect on the hypothalamic-pituitary axis, endocrine glands function, and cause damage to bone epiphyses [9-11]. Since GH deficiency is one of the most common endocrinopathies among childhood cancer survivors, GH therapy offers possible beneficial 
Table III. Evaluation of anthropometric profile of patients according to weight-for-age and height-for-age z-scores differences between fourth (365 days post-transplant) and first (on admission) measurements

\begin{tabular}{|c|c|c|c|c|c|}
\hline Parameter & $n$ & $\begin{array}{c}\text { Difference in weight-for-age } \\
\text { z-score values* }\end{array}$ & p-value & $\begin{array}{c}\text { Difference in height-for-age } \\
\text { z-score values* }\end{array}$ & p-value \\
\hline All patients & 79 & $-0.32 \pm 0.96$ & & $-0.28 \pm 0.72$ & \\
\hline Age group & & & 0.17 & & 0.12 \\
\hline$<10$ years & 39 & $-0.44 \pm 1.07$ & & $-0.38 \pm 0.91$ & \\
\hline$\geq 10$ years & 40 & $-0.20 \pm 0.83$ & & $-0.18 \pm 0.46$ & \\
\hline Sex & & & 0.16 & & 0.26 \\
\hline Male & 54 & $-0.24 \pm 1.01$ & & $-0.23 \pm 0.79$ & \\
\hline Female & 25 & $-0.49 \pm 0.83$ & & $-0.38 \pm 0.55$ & \\
\hline Type of disease & & & 0.16 & & 0.95 \\
\hline Malignant & 61 & $-0.38 \pm 1.03$ & & $-0.26 \pm 0.77$ & \\
\hline Non-malignant & 18 & $-0.09 \pm 0.66$ & & $-0.34 \pm 0.51$ & \\
\hline Type of pretransplant conditioning & & & 0.09 & & 0.11 \\
\hline Myeloablative & 58 & $-0.44 \pm 0.9$ & & $-0.37 \pm 0.58$ & \\
\hline Non-myeloablative & 21 & $0.03 \pm 1.05$ & & $-0.02 \pm 0.98$ & \\
\hline TBI-based regimen & & & 0.01 & & 0.48 \\
\hline Yes & 31 & $-0.59 \pm 0.88$ & & $-0.33 \pm 0.53$ & \\
\hline No & 48 & $-0.14 \pm 0.98$ & & $-0.24 \pm 0.82$ & \\
\hline Parenteral nutrition in HSCT period & & & 0.56 & & 0.01 \\
\hline Yes & 50 & $-0.33 \pm 1.14$ & & $-0.39 \pm 0.83$ & \\
\hline No & 29 & $-0.30 \pm 0.54$ & & $-0.08 \pm 0.39$ & \\
\hline Stage III-IV mucositis & & & 0.71 & & 0.49 \\
\hline Yes & 34 & $-0.30 \pm 0.88$ & & $-0.22 \pm 0.53$ & \\
\hline No & 45 & $-0.33 \pm 1.03$ & & $-0.33 \pm 0.85$ & \\
\hline Acute GvHD & & & 0.047 & & 0.75 \\
\hline Yes & 26 & $-0.53 \pm 1.19$ & & $-0.27 \pm 1.00$ & \\
\hline No & 53 & $-0.22 \pm 0.83$ & & $-0.30 \pm 0.54$ & \\
\hline Acute GvHD of gastrointestinal tract & & & 0.17 & & 0.01 \\
\hline Yes & 13 & $-0.38 \pm 1.50$ & & $-0.51 \pm 1.31$ & \\
\hline No & 66 & $-0.31 \pm 0.54$ & & $-0.23 \pm 0.53$ & \\
\hline Chronic GvHD & & & 0.2 & & 0.04 \\
\hline Yes & 25 & $-0.42 \pm 1.31$ & & $-0.41 \pm 1.08$ & \\
\hline No & 54 & $-0.27 \pm 0.76$ & & $-0.22 \pm 0.45$ & \\
\hline Chronic GvHD of gastrointestinal tract & & & 0.11 & & 0.05 \\
\hline Yes & 12 & $-0.79 \pm 0.88$ & & $-0.69 \pm 0.72$ & \\
\hline No & 67 & $-0.23 \pm 0.96$ & & $-0.2 \pm 0.7$ & \\
\hline
\end{tabular}

*Fourth vs. first measurement; TBI - total body irradiation; HSCT - hematopoietic stem cell transplantation; GvHD - graft versus host disease 
management of decreased growth [10]. Additionally, only a few studies have aimed to investigate nutritional status and body composition abnormalities in cancer survivors. A report of the Childhood Cancer Survivor Study showed that underweight HSCT survivors are more likely to suffer from major medical conditions, and need to be monitored for negative health consequences of abnormal BMI [12].

Our study is one of the first to investigate the risk factors for early growth retardation in children treated with HSCT. So far, few studies have focused on this issue. A short-term follow-up study comprising 123 adult patients found that being male, an allogeneic transplant, and a length of stay in hospital > 21 days were all factors associated with greater deterioration of nutritional status [26]. Moreover, Campos et al. found that total dose of corticosteroids, length of their use, and the type of HSCT donor were all risk factors for lean body mass changes in a 6-month follow-up period [24]. We found the presence of acute GvHD to be a possible factor impeding weight gain, and we found acute GvHD of the Gl tract or chronic GvHD to affect height gain. Acute and chronic GvHD include multiple manifestations and can affect any segment of the GI tract, causing a variety of Gl symptoms. Mucosal injury of intestines results in protein loss, which subsequently leads to malabsorption and malnutrition [27]. To date, the results describing the association between acute GvHD and weight and height changes are inconsistent. Contrary to our study, a report on 45 children treated with HSCT showed no association between the presence of Gl symptoms in patients with GvHD and anthropometric measurements four months after HSCT; however, this study group was relatively small, which might have impeded analysis [28]. Chronic GvHD is a leading cause of long-term mortality in HSCT recipients and can occur at any time after HSCT. To date, a few studies have shown that patients with chronic GVHD were more likely to report shorter final height and significant weight loss [10, 29].

TBI remains a well-known factor altering final height of HSCT recipients due to its impact on endocrine and skeletal systems $[8,11]$. Our study found it to be also an important risk factor for weight loss in short-term follow-up. Furthermore, we demonstrated that the use of parenteral nutrition in the peritransplant period is a risk factor for a severe deterioration in height gain. According to the ESPEN Guidelines, parenteral nutrition is recommended as nutritional support where oral and enteral nutrition is insufficient or unfeasible [30]. As far as we know, there has been no study evaluating the height of patients who underwent HSCT and who were fed with parenteral nutrition. A recent systematic review found that patients receiving enteral nutrition had lower weight-for-height z-scores than those receiving parenteral nutrition on admission and 30 days post-transplant. However, it did not evaluate the height of patients [20].
Our study has several limitations. Firstly, due to the low number of pediatric HSCT recipients, our study group (79 patients) is relatively small. Secondly, our study included only Polish children; the anthropometric profile may differ in other populations. Our results cannot be easily extrapolated to patients with primary immunodeficiencies and short stature phenotype, since they were excluded from the study.

Nevertheless, thanks to this criterion, our study group seems to present a healthy population and to be a good model to show alterations in growth patterns. Another downside is the retrospective character of this study and the limitations linked to that. Due to this fact, we were confronted by missing data, and as a result had to exclude some patients.

\section{Conclusions}

In conclusion, we demonstrated that weight-for-age and height-for-age z-scores of pediatric patients significantly declined throughout a one-year follow-up. Patients who received TBI before $\mathrm{HSCT}$, who were fed with parenteral nutrition, or who were complicated with GvHD, especially localized in the Gl tract, require prolonged and close weight and height monitoring, since we have found them to be at increased risk for deteriorations in weight and height gain. Future larger studies are warranted to validate these findings.

\section{Data availability statement}

The data that supports the findings of this study is available from the corresponding author upon request.

\section{Author's contributions}

All authors confirm they had full access to data and contributed to the drafting of this paper. MK and JG designed and coordinated the study. MK, AK, AAS and AC analyzed the data and wrote sections of the manuscript. All authors were responsible for the integrity and accuracy of the data, and approved the submitted version.

\section{Conflict of interest}

None.

\section{Financial support \\ None.}

\section{Ethics}

The work described in this article has been carried out in accordance with The Code of Ethics of the World Medical Association (Declaration of Helsinki) for experiments involving humans; EU Directive 2010/63/EU for animal experiments; Uniform Requirements for Manuscripts submitted to Biomedical Journals. 


\section{References}

1. Passweg JR, Baldomero H, Bader P, et al. European Society for Blood and Marrow Transplantation (EBMT). Is the use of unrelated donor transplantation leveling off in Europe? The 2016 European Society for Blood and Marrow Transplant activity survey report. Bone Marrow Transplant. 2018; 53(9): 1139-1148, doi: 10.1038/s41409-0180153-1, indexed in Pubmed: 29540849.

2. Majhail NS, Tao Li, Bredeson C, et al. Prevalence of hematopoietic cell transplant survivors in the United States. Biol Blood Marrow Transplant. 2013; 19(10): 1498-1501, doi: 10.1016/j.bbmt.2013.07.020, indexed in Pubmed: 23906634.

3. Wingard JR, Majhail NS, Brazauskas R, et al. Long-term survival and late deaths after allogeneic hematopoietic cell transplantation. J Clin Oncol. 2011; 29(16): 2230-2239, doi: 10.1200/JC0.2010.33.7212, indexed in Pubmed: 21464398.

4. Armenian SH, Sun $\mathrm{CL}$, Kawashima T, et al. Long-term health-related outcomes in survivors of childhood cancer treated with HSCT versus conventional therapy: a report from the Bone Marrow Transplant Survivor Study (BMTSS) and Childhood Cancer Survivor Study (CCSS). Blood. 2011; 118(5): 1413-1420, doi: 10.1182/ /blood-2011-01-331835, indexed in Pubmed: 21652685.

5. Martin-Salces M, de Paz R, Canales MA, et al. Nutritional recommendations in hematopoietic stem cell transplantation. Nutrition. 2008; 24(7-8): 769-775, doi: 10.1016/j.nut.2008.02.021, indexed in Pubmed: 18468863.

6. Chow EJ, Friedman DL, Yasui Y, et al. Decreased adult height in survivors of childhood acute lymphoblastic leukemia: a report from the Childhood Cancer Survivor Study. J Pediatr. 2007; 150(4): 370-5, 375. e1, doi: 10.1016/j.jpeds.2006.11.036, indexed in Pubmed: 17382112.

7. Inaba H, Yang J, Kaste SC, et al. Longitudinal changes in body mass and composition in survivors of childhood hematologic malignancies after allogeneic hematopoietic stem-cell transplantation. J Clin Oncol. 2012; 30(32): 3991-3997, doi: 10.1200/JC0.2011.40.0457, indexed in Pubmed: 23032628.

8. Cohen A, Rovelli A, Bakker B, et al. Final height of patients who underwent bone marrow transplantation for hematological disorders during childhood: a study by the Working Party for Late Effects-EBMT. Blood. 1999; 93(12): 4109-4115, indexed in Pubmed: 10361107.

9. Afify Z, Shaw PJ, Clavano-Harding A, et al. Growth and endocrine function in children with acute myeloid leukaemia after bone marrow transplantation using busulfan/cyclophosphamide. Bone Marrow Transplant. 2000; 25(10): 1087-1092, doi: 10.1038/ /sj.bmt.1702384, indexed in Pubmed: 10828870.

10. Isfan F, Kanold J, Merlin E, et al. Growth hormone treatment impact on growth rate and final height of patients who received HSCT with TBI or/and cranial irradiation in childhood: a report from the French Leukaemia Long-Term Follow-Up Study (LEA). Bone Marrow Transplant. 2012; 47(5): 684-693, doi: 10.1038/bmt.2011.139, indexed in Pubmed: 21725370.

11. Bernard F, Bordigoni P, Simeoni MC, et al. Height growth during adolescence and final height after haematopoietic SCT for childhood acute leukaemia: the impact of a conditioning regimen with $\mathrm{BU}$ or TBI. Bone Marrow Transplant. 2009; 43(8): 637-642, doi: 10.1038/ /bmt.2008.370, indexed in Pubmed: 19011662.

12. Meacham LR, Gurney JG, Mertens AC, et al. Body mass index in long-term adult survivors of childhood cancer: a report of the Childhood Cancer Survivor Study. Cancer. 2005; 103(8): 1730-1739, doi: 10.1002/cncr.20960, indexed in Pubmed: 15761876.
13. Ringwald-Smith KA, Heslop HE, Krance RA, et al. Energy expenditure in children undergoing hematopoietic stem cell transplantation. Bone Marrow Transplant. 2002; 30(2): 125-130, doi: 10.1038/ /sj.bmt.1703608, indexed in Pubmed: 12132052.

14. Hutchinson ML, Clemans GW, Springmeyer SC, et al. Energy expenditure estimation in recipients of marrow transplants. Cancer. 1984; 54(8): 1734-1738, doi: 10.1002/1097-0142(19841015)54:8<1734::aid-cncr2820540844>3.0.c0;2-0, indexed in Pubmed: 6383597.

15. Zemrani B, Yap JK, Van Dort B, et al. Nutritional challenges in children with primary immunodeficiencies undergoing hematopoietic stem cell transplant. Clin Nutr. 2020; 39(9): 2832-2841, doi: 10.1016/j. clnu.2019.12.015, indexed in Pubmed: 31952894.

16. da Costa Heinen GT, Schmit D, Campos DJ, et al. Short-term follow-up of the nutritional status of children with Fanconi anemia undergoing hematopoietic stem cell transplant. Support Care Cancer. 2018; 26(3): 895-903, doi: 10.1007/s00520-017-3906-2, indexed in Pubmed: 28975509.

17. Elm Ev, Altman D, Egger M, et al. The Strengthening the Reporting of Observational Studies in Epidemiology (STROBE) statement: guidelines for reporting observational studies. J Clin Epidemiol. 2008; 61(4): 344-349, doi: 10.1016/j.jclinepi.2007.11.008, indexed in Pubmed: 18313558.

18. Przepiorka D, Weisdorf D, Martin P, et al. 1994 Consensus Conference on Acute GVHD Grading. Bone Marrow Transplant. 1995; 15(6): 825-828, indexed in Pubmed: 7581076.

19. Singh N, Loren AW. Overview of hematopoietic cell transplantation for the treatment of hematologic malignancies. Clin Chest Med. 2017; 38(4): 575-593, doi: 10.1016/j.ccm.2017.07.001, indexed in Pubmed: 29128011.

20. Evans JC, Hirani SP, Needle JJ. Nutritional and post-transplantation outcomes of enteral versus parenteral nutrition in pediatric hematopoietic stem cell transplantation: a systematic review of randomized and nonrandomized studies. Biol Blood Marrow Transplant. 2019; 25(8): e252-e259, doi: 10.1016/j.bbmt.2019.02.023, indexed in Pubmed: 30826462.

21. Bicakli DH, Yilmaz MC, Aksoylar S, et al. Enteral nutrition is feasible in pediatric stem cell transplantation patients. Pediatr Blood Cancer. 2012; 59(7): 1327-1329, doi: 10.1002/pbc.24275, indexed in Pubmed: 22911565.

22. Gonzales F, Bruno B, Alarcón Fuentes M, et al. Better early outcome with enteral rather than parenteral nutrition in children undergoing MAC allo-SCT. Clin Nutr. 2018; 37(6 Pt A): 2113-2121, doi: 10.1016/j. clnu.2017.10.005, indexed in Pubmed: 29097037.

23. Azarnoush S, Bruno B, Beghin L, et al. Enteral nutrition: a first option for nutritional support of children following allo-SCT? Bone Marrow Transplant. 2012; 47(9): 1191-1195, doi: 10.1038/bmt.2011.248, indexed in Pubmed: 22231466.

24. Campos DJ, Boguszewski CL, Funke VA, et al. Bone mineral density, vitamin $\mathrm{D}$, and nutritional status of children submitted to hematopoietic stem cell transplantation. Nutrition. 2014; 30(6): 654-659, doi: 10.1016/j.nut.2013.10.014, indexed in Pubmed: 24613437.

25. Demoor-Goldschmidt C, Allodji RS, Journy N, et al. Risk factors for small adult height in childhood cancer survivors. J Clin Oncol. 2020; 38(16): 1785-1796, doi: 10.1200/JC0.19.02361, indexed in Pubmed: 32196392.

26. Barritta de Defranchi RL, Bordalejo A, Cañueto I, et al. Evolution of nutritional status in patients with autologous and allogeneic hematopoietic stem cell transplant. Support Care Cancer. 2015; 23(5): 1341-1347, doi: 10.1007/s00520-014-2473-z, indexed in Pubmed: 25347950. 
27. Naymagon S, Naymagon L, Wong SY, et al. Acute graft-versus-host disease of the gut: considerations for the gastroenterologist. Nat Rev Gastroenterol Hepatol. 2017; 14(12): 711-726, doi: 10.1038/ /nrgastro.2017.126, indexed in Pubmed: 28951581.

28. Rodgers C, Wills-Alcoser P, Monroe R, et al. Growth patterns and gastrointestinal symptoms in pediatric patients after hematopoietic stem cell transplantation. Oncol Nurs Forum. 2008; 35(3): 443-448, doi: 10.1188/08.0NF.443-448, indexed in Pubmed: 18467293.
29. Browning B, Thormann K, Seshadri R, et al. Weight loss and reduced body mass index: a critical issue in children with multiorgan chronic graft-versus-host disease. Bone Marrow Transplant. 2006; 37(5): 527-533, doi: 10.1038/sj.bmt.1705268, indexed in Pubmed: 16435019.

30. Arends J, Bachmann P, Baracos V, et al. ESPEN guidelines on nutrition in cancer patients. Clin Nutr. 2017; 36(1): 11-48, doi: 10.1016/j. clnu.2016.07.015, indexed in Pubmed: 27637832.

\section{Supplement 1}

Table S1. STROBE Statement

\begin{tabular}{|c|c|c|}
\hline & $\begin{array}{l}\text { Item } \\
\text { no. }\end{array}$ & Recommendation \\
\hline $\begin{array}{l}\text { aABS Title } \\
\text { and abstract }\end{array}$ & 1 & $\begin{array}{l}\text { (a) Indicate study's design with commonly used term in title or abstract } \\
\text { (b) Provide in the abstract an informative and balanced summary of what was done } \\
\text { and what was found }\end{array}$ \\
\hline Introduction & & \\
\hline $\begin{array}{l}\text { Background/rationale } \\
\text { Objectives }\end{array}$ & $\begin{array}{l}2 \\
3\end{array}$ & $\begin{array}{l}\text { Explain the scientific background and rationale for the investigation being reported } \\
\text { State specific objectives, including any prespecified hypotheses }\end{array}$ \\
\hline Methods & & \\
\hline Study design & 4 & Present key elements of study design early in the paper \\
\hline Setting & 5 & $\begin{array}{l}\text { Describe the setting, locations, and relevant dates, including periods of recruitment, } \\
\text { exposure, follow-up, and data collection }\end{array}$ \\
\hline Participants & 6 & $\begin{array}{l}\text { (a) Give the eligibility criteria, and the sources and methods of selection of participants. } \\
\text { Describe methods of follow-up } \\
\text { (b) For matched studies, give matching criteria and number of exposed and unexposed }\end{array}$ \\
\hline Variables & 7 & $\begin{array}{l}\text { Clearly define all outcomes, exposures, predictors, potential confounders, and effect } \\
\text { modifiers. Give diagnostic criteria, if applicable }\end{array}$ \\
\hline $\begin{array}{l}\text { Data sources/ mea- } \\
\text { surement }\end{array}$ & $8^{*}$ & $\begin{array}{l}\text { For each variable of interest, give sources of data and details of methods of as- } \\
\text { sessment (measurement). Describe comparability of assessment methods if there is } \\
\text { more than one group }\end{array}$ \\
\hline Bias & 9 & Describe any efforts to address potential sources of bias \\
\hline Study size & 10 & Explain how the study size was arrived at \\
\hline Quantitative variables & 11 & $\begin{array}{l}\text { Explain how quantitative variables were handled in the analyses. If applicable, describe } \\
\text { which groupings were chosen and why }\end{array}$ \\
\hline Statistical methods & 12 & $\begin{array}{l}\text { (a) Describe all statistical methods, including those used to control for confounding } \\
\text { (b) Describe any methods used to examine subgroups and interactions } \\
\text { (c) Explain how missing data was addressed } \\
\text { (d) If applicable, explain how loss to follow-up was addressed } \\
\text { (e) Describe any sensitivity analyses }\end{array}$ \\
\hline
\end{tabular}

Results

Participants

13* (a) Report numbers of individuals at each stage of study - e.g. numbers potentially eligible, examined for eligibility, confirmed eligible, included in the study, completing follow-up, and analysed

(b) Give reasons for non-participation at each stage

Consider use of a flow diagram 
Table S1 (cont.). STROBE Statement

\begin{tabular}{|c|c|c|c|}
\hline & $\begin{array}{l}\text { Item } \\
\text { no. }\end{array}$ & Recommendation & $\begin{array}{l}\text { Reported } \\
\text { on page }\end{array}$ \\
\hline Descriptive data & $14 *$ & $\begin{array}{l}\text { (a) Give characteristics of study participants (e.g. demographic, clinical, social) and } \\
\text { information on exposures and potential confounders } \\
\text { (b) Indicate number of participants with missing data for each variable of interest } \\
\text { (c) Summarize follow-up time (e.g. average and total amount) }\end{array}$ & $\begin{array}{l}6,7 \\
\text { Table } 1 \\
\text { NA } \\
\text { Table } 1\end{array}$ \\
\hline Outcome data & $15^{*}$ & Report numbers of outcome events or summary measures over time & $\begin{array}{l}7, \\
\text { Table 2, } \\
\text { Table } 3\end{array}$ \\
\hline \multirow[t]{3}{*}{ Main results } & 16 & $\begin{array}{l}\text { (a) Give unadjusted estimates and, if applicable, confounder-adjusted estimates and } \\
\text { their precision (e.g. } 95 \% \text { confidence interval). Make clear which confounders were adju- } \\
\text { sted for and why they were included }\end{array}$ & NA \\
\hline & & (b) Report category boundaries when continuous variables were categorized & $\begin{array}{l}4,5 \\
\text { (descri- } \\
\text { bed in } \\
\text { Methods } \\
\text { section) }\end{array}$ \\
\hline & & $\begin{array}{l}\text { (c) If relevant, consider translating estimates of relative risk into absolute risk for a me- } \\
\text { aningful time period }\end{array}$ & NA \\
\hline Other analyses & 17 & $\begin{array}{l}\text { Report other analyses done - e.g. analyses of subgroups and interactions, and sensiti- } \\
\text { vity analyses }\end{array}$ & 8 \\
\hline \multicolumn{4}{|l|}{ Discussion } \\
\hline Key results & 18 & Summarize key results with reference to study objectives & 9 \\
\hline Limitations & 19 & $\begin{array}{l}\text { Discuss limitations of the study, taking into account sources of potential bias or impre- } \\
\text { cision. Discuss both direction and magnitude of any potential bias }\end{array}$ & 12 \\
\hline Interpretation & 20 & $\begin{array}{l}\text { Give a cautious overall interpretation of results considering objectives, limitations, mul- } \\
\text { tiplicity of analyses, results from similar studies, and other relevant evidence }\end{array}$ & $9-12$ \\
\hline Generalisability & 21 & Discuss the generalizability (external validity) of the study results & 12 \\
\hline \multicolumn{4}{|l|}{ Other information } \\
\hline Funding & 22 & $\begin{array}{l}\text { Give the source of funding and the role of the funders for the present study and, if } \\
\text { applicable, for the original study on which the present article is based }\end{array}$ & 13 \\
\hline
\end{tabular}

*Give information separately for exposed and unexposed groups

Note: An Explanation and Elaboration article discusses each checklist item and gives methodological background and published examples of transparent reporting. The STROBE checklist is best used in conjunction with this article (freely available on the websites of PLoS Medicine at http://www.plosmedicine.org/, Annals of Internal Medicine at http://www.annals.org/, and Epidemiology at http://www. epidem.com/). Information on the STROBE Initiative is available at http://www.strobe-statement.org 